DOI: http://dx.doi.org/10.33846/hn40703

http://heanoti.com/index.php/hn

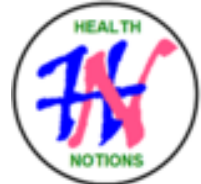

RESEARCH ARTICLE

URL of this article: http://heanoti.com/index.php/hn/article/view/hn40703

\title{
The Experiences of Emergency Nurses During the Covid-19 Crisis: Factor Analysis
}

\author{
Ahmed Atallah AlQurash ${ }^{1}$, Abdullelah Al Thobaity ${ }^{2 \mathrm{CA}}$, Modi Owied Al Moteri ${ }^{3}$, Mohammed Almalki ${ }^{4}$, \\ Waleed Ali Alahmari ${ }^{5}$ \\ ${ }^{1}$ Nursing Department, King Faisal Medical Complex / Nursing Department, College of Applied Medical \\ Sciences, Taif University; Saudi Arabia; abogarash2040@gmail.com \\ ${ }^{2(\mathrm{CA})}$ Nursing Department, College of Applied Medical Sciences, Taif University; Saudi Arabia; \\ a.thobaity@tu.edu.sa (Corresponding Author) \\ ${ }^{3}$ Nursing Department, College of Applied Medical Sciences, Taif University; Saudi Arabia; \\ m.motairy@tu.edu.sa \\ ${ }^{4}$ Nursing, College of Applied Medical Sciences, Taif University; Saudi Arabia; mhdalmalki51@gmail.com \\ ${ }^{5}$ Nursing, College of Applied Medical Sciences, Taif University; Saudi Arabia; waleed.alahmari @hotmail.com
}

\begin{abstract}
Emergency nurses are in the frontline in managing COVID-19 crises. Directly encountering and dealing with infected patients put nurses at high risk. To date, evidence about emergency nurses' experiences of COVID-19, particularly those in the frontline, are limited. Understanding the experience and impact of the COVID-19 crisis on emergency nurses could contribute to improving nursing and disaster practices. This study aimed to explore the experiences of emergency nurses during their responses to the COVID-19 crisis. Thus, A cross-sectional design was used. For the data collection, a questionnaire was constructed and its validity and reliability was rigorously evaluated by principle component analysis (PCA), exploratory factor analysis (EFA), and confirmatory factor analysis (CFA). The data were collected in two phases, in which 111 and 128 emergency nurses were recruited from different hospitals in Saudi Arabia. The primary purpose of PCA; EFA and CFA to delete weak loading and extract and confirm factors. The findings of using factor analysis, of the 22 items, 11 items were retained with strong factor loadings ( 0.88 to 0.54$)$ to three factors. The three factors were worry (4 items), compliance (4 items), and cautiousness ( 3 items). The reliability of the three factors was $0.84,0.86$, and 0.73 , respectively, indicating that the scale had good reliability. The 11 scale items had robust psychometric properties, which implies that they could be used to evaluate emergency nurses' experience in encountering and dealing with the COVID-19 crisis. Although nurses in the frontline showed compliance with infection control prevention measures, they were likely to experience certain degrees of fear and worry, which could lead to burnout. Hence, it is highly recommended to help nurses overcome such crises by providing consistent support and reassurance.
\end{abstract}

Keywords: mmergency nursing; COVID-19; crisis; nursing care and experiences

\section{INTRODUCTION}

Because the primary responsibility of governments in many countries is to reduce the risk of COVID-19 and prevent the spread of the virus, they have taken measures to save lives and ensure health. Such measures involve engaging the entire society in the decision to cancel all community events that have the potential to spread COVID-19. Although these measures have contributed to preventing infection and reducing mortality rates, they might have negative effects on both the economy and health, including institutions and personnel ${ }^{(1,2)}$. The healthcare system is of utmost importance in responding to this crisis. Consequently, the COVID-19 virus has overburdened healthcare systems across the world countries. In hospitals, all patients must be treated and isolated to control the spread of the infection. Specifically, in 190 countries, among the hospital functions that 
were affected by the COVID-19 crisis during a period of 12 weeks included the cancellation of 28 million operations ${ }^{(3)}$. Additionally, several hospitals across the world have been overwhelmed by the rapidly increasing number COVID-19 cases, which forced the authorities to build field hospitals that were designed mainly for pandemics such as the coronavirus infection ${ }^{(4-6)}$. In addition to bed capacity, the COVID-19 pandemic has impacted hospital personnel because it has created a significant shortage in the number of healthcare providers, such as nurses, who comprised the largest group. The backbone of any healthcare institution worldwide, nurses have significant roles in responding to disasters, including those related to pandemics ${ }^{(2,7,8)}$.

The pandemic literature shows that several issues have faced nurses worldwide during their response to COVID-19, which are summarized as follows: (A) Nurses experience psychological distress and anxiety; thus, it is highly recommended to pay attention to their psychological issues on the frontline ${ }^{(9,10)}$. (B) The limited knowledge of COVID-19 among nurses was evident in a study published in Iran, which found that $43 \%$ of the participant nurses had lower than "cut-off" knowledge ${ }^{(11)}$. (C) In responding to the COVID-19 pandemic, nurses and other healthcare providers experience grief due to the daily deaths of patients and related ethical issues because of the lack of medical supplies such as ventilators ${ }^{(12,13)}$. (D) Nurses risk being infected by the coronavirus. More than 3,000 medical providers, including nurses, were infected by COVID-19 in China, and several deaths among doctors and nurses were reported in Italy ${ }^{(14,15)}$. (E) Nurses struggle with ethical issues regarding the death of patients from COVID-19 ${ }^{(16)}$. (F) Nurses face a critical shortage of medical supplies, such as PPE and beds, which exacerbates their risk of infection ${ }^{(8,17)}$. These issues are not identical in all countries, and they vary from one country to another.

In Saudi Arabia, despite the huge cost to the Saudi economy, several decisions were made regarding social activities, such as sports, praying at mosques, and attending schools and universities. Further measures taken by the Saudi Arabian government included the restrictions on travel and informing the importance of keeping social distancing and reducing the close contact with large groups ${ }^{(18)}$. In addition, the Umrah and Hajji events were suspended temporarily to ensure human safety because of the high potential to spread the infection $^{(19)}$. In 2012, the Ministry of Health and Hospital Administration in Saudi Arabia experienced a coronavirus infection, which was known as the Middle-East respiratory syndrome-coronavirus (MERS-CoV). In previous research, issues related to MERS-CoV were explored and described to investigate the level of knowledge of healthcare providers including nurses. The results of a study conducted in Najran City indicated that the majority of healthcare providers had a high level of knowledge of MERS-CoV and that they had a positive attitude toward their response to the MERS-CoV crisis ${ }^{(20)}$. In addition, some educational and training programs were designed for nurse educators, which involved triage, personal protective equipment such as masks and hand hygiene, and nasopharyngeal swabs ${ }^{(21)}$.

Although Saudi nurses have had experiences that differ from those of nurses in the rest of the world, the emergency nursing literature in Saudi Arabia lacks evidence on how they have dealt with COVID-19, particularly as the mortality and infection rates have exceeded those caused by MERS-CoV. Therefore, exploring emergency nurses' experiences and identifying the factors related to those in the frontline during the COVID-19 crisis will contribute to the following: policymaking for infection control; nursing practice and disaster nursing in pandemics; effective responses to and rapid recovery from such crises. Knowledge of their experiences will enhance the development of nursing practice by drawing on the perspectives and experiences of nurses, who are the largest group in the healthcare system. Thus, the aim of this study is to explore the experiences of emergency nurses during their responses to the COVID-19 crisis.

\section{METHODS}

In this research, a cross-sectional survey of emergency nurses was conducted in hospitals in Saudi Arabia, utilizing Principle Component Analysis (PCA), Exploratory Factor Analysis (EFA), and Confirmatory Factor Analysis (CFA). The study was conducted in two phases: in the first phase, the data were collected, and the primary factors related to the nurse's experiences during their response to COVID-19 were extracted; in the second phase, the structure of the extracted data was confirmed using PCA.

\section{Sampling}

This study was conducted in five major hospitals that are operated by the Ministry of Health in Taif City and Makkah City. The population selected for this study comprised registered emergency nurses who were working in government hospitals in these cities. Non-random, convenience sampling questionnaires were distributed in English because it is the main communication language in all hospitals in Saudi Arabia. To meet the requ irements of PCA, EFA, and CFA, the sample must consist of more than 100 participants. 


\section{Ethical Consideration}

This study was conducted after ethical approval was obtained from the Ministry of Health. The IRB registration number by KACST KSA is HAP-02-T-067, and the approval number is 352, dated 03-05-2020.

\section{Instrument and Data Collection}

The authors of this study created a scale for collecting data from the emergency nurses in the sample. The scale was based on nurses' experiences in the literature, and some items were added by experts in the emergency departments $^{(22)}$. Validity and reliability were rigorously evaluated by PCA, EFA, and CFA to ensure that the findings were valid and reliable. The survey contained two parts: the first part comprised demographic data on the participants, including age, gender, experience, position, sources of information, and number of working hours. The second part explored the emergency nurses' experiences during their responses to COVID-19, which involved 22 items using a Likert scale $(1=$ strongly disagree; $2=$ disagree; $3=$ neutral; $4=$ agree; $5=$ strongly agree). The phase validity and content validity were evaluated by a panel of experts, and the construct validity and discrimination validity were tested statistically.

The data were collected in two phases: in the first phase, data were collected at three hospitals from 5 May 2020 to 15 May 2020; in the second phase, data were collected at two hospitals on 26 May 2020. Survey monkey was used to collect the data; the surveys were sent to the participants' email addresses or their WhatsApp accounts. In the first phase, the data were used to remove redundant items (i.e., weak loading and cross loading); in the second phase, the data were used to extract and confirm related factors.

\section{Data Analysis}

The collected data were prepared for analysis by checking for missing data, outlier data, and normal distribution, which is required by the PCA and the CFA. In the first phase, the data were analyzed using the PCA protocol, which consisted of five steps. In the first step, the suitability of the data for the PCA was determined. In this study, the suitability of the data was enhanced by the number of participants, which was more than $100^{(22,23)}$. The Kaiser-Mayer-Olkin (KMO) and Bartlett's tests were used to determine the accepted range of the KMO. Bartlett's test showed more than 0.50, which was significant at p > 0.05 (24). In the second step, the factors were extracted using PCA, as it was suitable for removing the redundant items ${ }^{(25)}$. In the third step, the criteria for extracting the factors were selected: the cumulative percentage of variance was more than 50 to 60 . In this study, the eigenvalue was used to select the number of the factors to be extracted, the values of which were 1 and above. In addition, a scree test was performed to identify the number of factors. In the fourth step, a rotation test was conducted to simplify the factor structure and facilitate the data analysis ${ }^{(25)}$. In this study, the varimax method was used because it provides results that are easily interpreted, especially in the nursing and social sciences ${ }^{(22)}$. Finally, after cross loading and the deletion of redundant items, the factors were interpreted and labeled according to their content.

CFA is the second type of factor analysis that was used to confirm the model's fitness. After the exploratory analysis, AMOS version 24 was used in the second phase of the data analysis following the same PCA process, except factor analysis principal axis factoring (PAF) was used for the extraction and quartimax was used for the rotation. The reason is that PAF is marginally more accurate than CFA in estimating population patterns for simple solutions ${ }^{(22,25)}$. The chi-square, GFI, RMR, CFI, RFI DELTA2, RMESA, TLI = rho2, and standardized RMR tests were applied. The variance estimation was used to determine the critical ratio of all confirmed parameters. Both SPSS version $24^{(26)}$ and AMOS version $23^{(27)}$ were used to analyze the data.

\section{RESULTS}

The study sample comprised 111 nurses. Around $75 \%$ of the participants were female nurses, and the rest were male nurses. More than $65 \%$ of the participants were below 35 years old. The majority of the participants obtained their knowledge from the Saudi Ministry of Health. Approximately 25\% of the staff nurses worked 12 hours per day during the COVID-19 crisis. Table 1 presents demographic information about the participants, included age, gender, sources of information about COVID-19, and hours of duty during the COVID-19 crisis. 
Table 1: Demographic data on the participants

\begin{tabular}{|c|c|c|c|}
\hline Demographic & Categories & Frequency & Percent \\
\hline \multirow[t]{4}{*}{ Age } & $18-25$ & 5 & 4.5 \\
\hline & $25-35$ & 70 & 63.1 \\
\hline & $35-50$ & 33 & 29.7 \\
\hline & Above & 3 & 2.7 \\
\hline \multirow[t]{2}{*}{ Gender } & Male & 28 & 25.2 \\
\hline & Female & 83 & 74.8 \\
\hline \multirow[t]{6}{*}{ Sources of information about COVID-19 } & Saudi Ministry of Health & 72 & 64.9 \\
\hline & World Health Organization & 21 & 18.9 \\
\hline & Social Media/Public news & 7 & 6.3 \\
\hline & Health Care Professional/ Colleague & 3 & 2.7 \\
\hline & Internet resources & 7 & 6.3 \\
\hline & Others & 1 & .9 \\
\hline \multirow[t]{2}{*}{ Hours of duty during COVID-19 } & $8 \mathrm{hrs}$ & 80 & 72.1 \\
\hline & $12 \mathrm{hrs}$ & 31 & 27.9 \\
\hline
\end{tabular}

The Kaiser-Meyer-Olkin measure was .82, and Bartlett's test of sphericity was significant at a chi-square $=$ 1187.63 and $\mathrm{p}=0.01$, which indicated that the sample size of 111 participants was adequate. The PCA method was used to exact the factors based on eigenvalues that must be more than 1 and based on cumulative percentage of variance that must be more than $50 \%$. Four factors were extracted from the data: factor 1; factor 2, factor 3 , and factor 4, which had eigenvalues higher than 1, as shown in Table 2. Accumulated explained variance of the four factors was achieved at $73.44 \%$ (four factors). Table 2 shows that the final criteria for deciding on the number of factors were based on the scree plot shown in Figure 1. All factors are shown about the elbow: the line in Figure 1 shows the level of the elbow, and the plots are the factors. Therefore, four factors were around the elbow, which were extracted, followed by the varimax rotation. After completing several iterations and deleting the redundant items, the items were arranged according to their loadings (i.e., coefficient score) from the highest to lowest. The cut-off point for loading was 0.40 without cross loading between the factors. Consequently, only six of 22 items were deleted because they were redundant (Table 2). The remaining 16 items were loaded to the four factors without cross loading or loading below 0.40 .

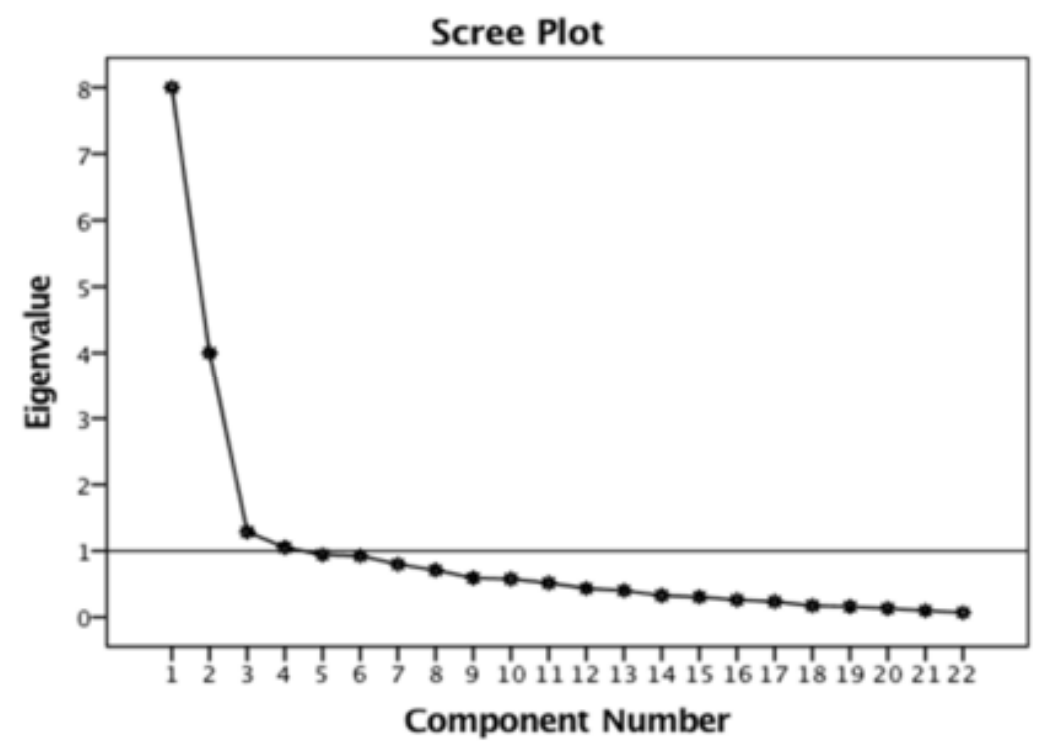

Figure 1. Scree plot for the first phase data PCA 
Table 2: Factors extracted using PCA with descriptive statistics

\begin{tabular}{|c|c|c|c|c|c|c|c|}
\hline \multirow[t]{2}{*}{ Items } & \multicolumn{4}{|c|}{ Factors } & \multicolumn{3}{|c|}{ Statistics } \\
\hline & 1 & 2 & 3 & 4 & $\mathrm{~m}$ & $\mathrm{Sd}$ & $\mathrm{h}$ \\
\hline $\begin{array}{l}\text { I'm keen to follow contact and airborne precautions when caring } \\
\text { for COVID-19 patients. }\end{array}$ & 0.90 & 0.01 & 0.20 & 0.03 & 4.25 & 1.16 & 0.87 \\
\hline $\begin{array}{l}\text { I'm keen to keep my knowledge updated about COVID-19 from } \\
\text { trustworthy sources. }\end{array}$ & 0.89 & 0.11 & 0.21 & 0.18 & 4.24 & 1.13 & 0.90 \\
\hline $\begin{array}{l}\text { I'm keen to keep my patients well-informed about the WHO } \\
\text { general recommendations for COVID-19 prevention. }\end{array}$ & 0.87 & 0.10 & 0.02 & 0.08 & 3.90 & 1.15 & 0.78 \\
\hline $\begin{array}{l}\text { I'm keen to follow the WHO general recommendations for } \\
\text { COVID-19 prevention in my practice. }\end{array}$ & 0.86 & 0.01 & 0.09 & 0.13 & 3.90 & 1.13 & 0.77 \\
\hline $\begin{array}{l}\text { Nurses should take special precautions during intubation by using } \\
\text { personal protective equipment (PPE). }\end{array}$ & 0.75 & 0.13 & 0.23 & 0.17 & 4.32 & 1.13 & 0.78 \\
\hline Preventive strategies cover the infection control measures. & 0.66 & -0.13 & 0.26 & 0.10 & 3.80 & 1.25 & 0.55 \\
\hline $\begin{array}{l}\text { I feel anxious when I talk to patients suspected of having the } \\
\text { coronavirus. }\end{array}$ & 0.05 & 0.85 & 0.11 & 0.09 & 2.73 & 1.11 & 0.76 \\
\hline I feel sad when I receive news of a new case being infected. & 0.29 & 0.69 & 0.02 & 0.23 & 3.13 & 1.05 & 0.62 \\
\hline I become anxious whenever I hear news about the coronavirus. & -0.11 & 0.68 & 0.26 & 0.22 & 2.38 & 1.20 & 0.61 \\
\hline $\begin{array}{l}\text { I almost never sleep because I think about the possibility of being } \\
\text { infected by the coronavirus. }\end{array}$ & -0.06 & 0.68 & 0.19 & 0.24 & 2.23 & 1.11 & 0.57 \\
\hline $\begin{array}{l}\text { I am worried that I might be infected with coronavirus, if I have a } \\
\text { flu or common cold. }\end{array}$ & 0.18 & 0.25 & 0.88 & 0.08 & 2.90 & 1.16 & 0.88 \\
\hline $\begin{array}{l}\text { I am worried about the risk of being infected by COVID-19 while } \\
\text { providing care for a confirmed COVID- } 19 \text { patient. }\end{array}$ & 0.27 & 0.24 & 0.86 & 0.14 & 3.38 & 1.24 & 0.90 \\
\hline $\begin{array}{l}\text { I am worried about my family because I know that the mortality } \\
\text { rate among COVID-19 patients is high. }\end{array}$ & 0.37 & 0.09 & 0.75 & 0.21 & 3.61 & 1.30 & 0.76 \\
\hline $\begin{array}{l}\text { I wash my hands using large amounts of disinfectant to protect } \\
\text { against the coronavirus. }\end{array}$ & 0.10 & 0.13 & 0.22 & 0.81 & 3.08 & 1.26 & 0.74 \\
\hline $\begin{array}{l}\text { I always wear an } \mathrm{N} 95 \text { respirator during my entire shift for } \\
\text { maximum protection. }\end{array}$ & 0.20 & 0.35 & 0.03 & 0.72 & 3.18 & 1.07 & 0.70 \\
\hline $\begin{array}{l}\text { I am frequently tested for } C O V I D-19 \text {, although } I \text { do not have } \\
\text { symptoms. }\end{array}$ & 0.22 & 0.30 & 0.11 & 0.71 & 3.22 & 1.18 & 0.67 \\
\hline Total explained variances & 28.90 & 16.18 & 15.58 & 12.77 & & & \\
\hline Eigenvalues & 6.512 & 2.89 & 1.42 & 1.1 & & & \\
\hline
\end{tabular}

$$
\mathrm{M}=\text { mean }
$$

On the first factor, six items were loaded from 0.90 to 0.66 . All six items explained the precautions that must be taken by the nurses in caring for COVID-19 patients $(\mathrm{M}=4.01, \mathrm{SD}=0.99)$. The highest loading was for using PPE in caring for patients with COVID-19 $(\mathrm{M}=4.25, \mathrm{SD}=1.16)$. The second highest loading was the importance of updating their knowledge $(\mathrm{M}=4.24, \mathrm{SD}=1.13)$. This factor explored the importance of utilizing the recommendations of WHO to either educate the patient $(\mathrm{M}=3.90, \mathrm{SD}=1.15)$ or follow them to prevent the spread of the infection $(\mathrm{M}=3.90, \mathrm{SD}=1.13)$. Regarding the second factor, $\mathrm{M}=2.62, \mathrm{SD}=0.86$. The loadings of the four items ranged from 0.85-0.68. The feeling of anxiety in talking to suspected patients (loading $=8.5$, $\mathrm{M}=2.73, \mathrm{SD}=1.11$, followed by feelings of sadness $(\mathrm{M}=3.13, \mathrm{SD}=1.05)$ and shortness of breath $(\mathrm{M}=2.38$, $\mathrm{SD}=1.20$ ) in hearing news about the coronavirus. The third factor was extracted from the data at $\mathrm{M}=3.30, \mathrm{SD}$ $=1.30$; three items were loaded on this factor with loading from $0.88-0.75$. The item regarding worrying if they had cold was the strongest loading on this factor $(M=2.90 ; S D=1.16)$, followed by anxiety about becoming infected $(\mathrm{M}=3.38, \mathrm{SD}=1.24)$ and anxious and being worried about their family $(\mathrm{M}=3.61, \mathrm{SD}=1.30$. The last factor was a $\mathrm{M}=3.16, \mathrm{SD}=0.91$. The loadings ranged from $0.81-0.71$, arranged from highest to lowest. The highest loading indicated that the nurses used excessive disinfection $(\mathrm{M}=3.08, \mathrm{SD}=1.26$; the second highest item was the use of protective masks in public places $(\mathrm{M}=3.18, \mathrm{SD}=1.07)$. the lowest, the rigorous adherence to medical guidelines for coronavirus was $\mathrm{M}=3.22, \mathrm{SD}=1.18$.

In the second stage of the data collection, 128 nurses participated at different hospitals in the same region. These data were collected for the purpose of confirming the factors extracted in the first phase. The KaiserMeyer-Olkin measure was .80, and Bartlett's test of sphericity was significant at chi-square $=726.39, \mathrm{p}=0.01$. Based on the eigenvalues, the explained communalities, the results of the scree test, the PAF for the extraction, and the quartimax using the Kaiser normalization for rotation, only three factors only could be extracted, as shown in Table 3 and Figure 2. 
Figure 2: Scree plot of the second phase data EFA

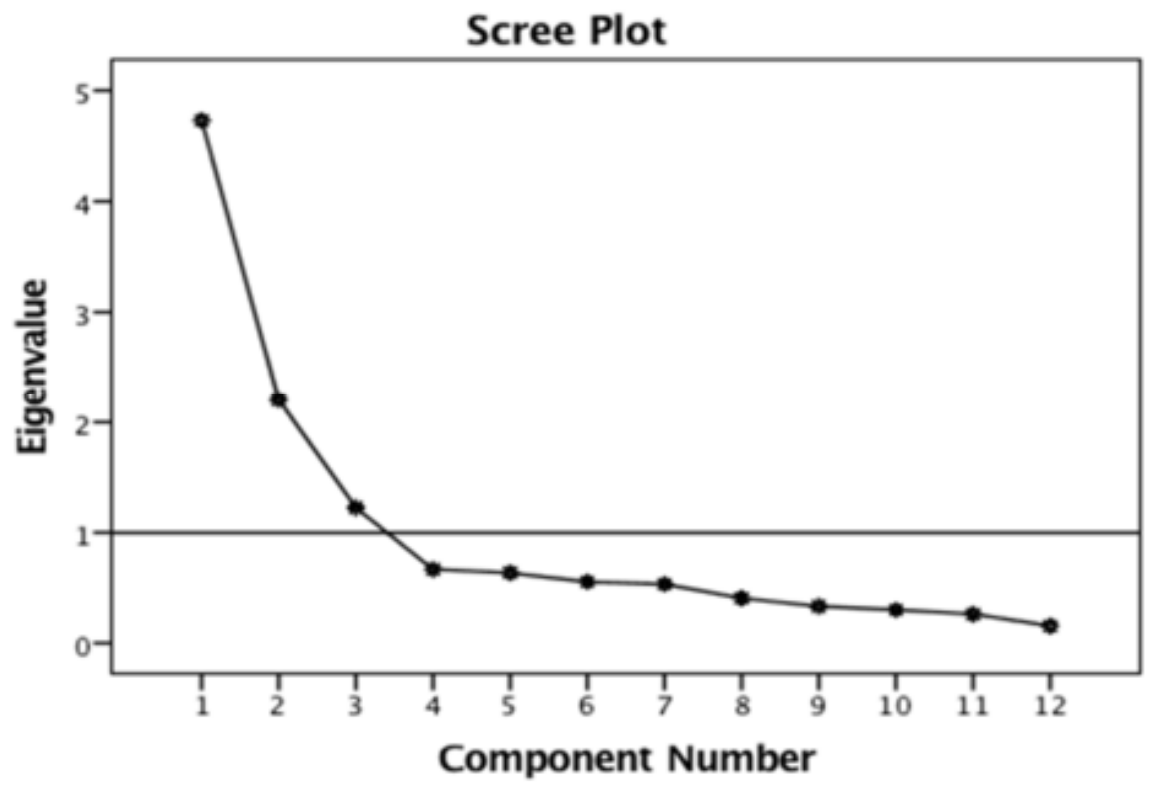

Figure 3: Scree plot of the second phase data EFA

Table 3. Factors extracted in the second phase using EFA

\begin{tabular}{|c|c|c|c|c|c|c|c|}
\hline \multirow[b]{2}{*}{ Items } & \multirow[t]{2}{*}{ Code } & \multicolumn{3}{|c|}{ Extracted factors } & \multicolumn{3}{|c|}{$\begin{array}{l}\text { Descriptive } \\
\text { statistics }\end{array}$} \\
\hline & & 1 & 2 & 3 & $\mathrm{H}$ & $\mathrm{M}$ & sd \\
\hline $\begin{array}{l}\text { I am worried that I might be infected with coronavirus, } \\
\text { if I have a flu or common cold. }\end{array}$ & A1 & 0.82 & 0.07 & 0.10 & 0.70 & 3.05 & 1.10 \\
\hline $\begin{array}{l}\text { I am worried about the risk of being infected with } \\
\text { COVID-19 while providing care to a } \\
\text { confirmed COVID-19 patient. }\end{array}$ & $\mathrm{A} 2$ & 0.79 & 0.21 & -0.00 & 0.68 & 3.21 & 1.19 \\
\hline $\begin{array}{l}\text { I am worried about my family because I know that the } \\
\text { mortality rates among COVID-19 patients are high. }\end{array}$ & A3 & 0.66 & 0.34 & -0.07 & 0.58 & 3.61 & 1.22 \\
\hline $\begin{array}{l}\text { I become anxious whenever I hear news about the } \\
\text { coronavirus. }\end{array}$ & A4 & 0.65 & 0.05 & 0.24 & 0.50 & 2.67 & 1.04 \\
\hline $\begin{array}{l}\text { I'm keen to keep my knowledge updated about } \\
\text { COVID-19 from trustworthy sources. }\end{array}$ & B1 & 0.16 & 0.88 & 0.03 & 0.81 & 3.05 & 1.10 \\
\hline $\begin{array}{l}\text { I'm keen to follow contact and airborne precautions } \\
\text { when caring for COVID-19 patients. }\end{array}$ & B2 & 0.16 & 0.77 & -0.05 & 0.64 & 4.21 & 1.06 \\
\hline $\begin{array}{l}\text { I'm keen to keep my patient well-informed about the } \\
\text { WHO general recommendations for COVID-19 } \\
\text { prevention. }\end{array}$ & B3 & 0.07 & 0.72 & 0.20 & 0.57 & 4.01 & 1.10 \\
\hline $\begin{array}{l}\text { I'm keen to follow the WHO general recommendations } \\
\text { for COVID-19 prevention in my practice. }\end{array}$ & B4 & 0.15 & 0.69 & 0.13 & 0.52 & 4.06 & 1.06 \\
\hline $\begin{array}{l}\text { I wash my hands using large amounts of disinfectant to } \\
\text { protect against the coronavirus. }\end{array}$ & $\mathrm{C} 1$ & 0.41 & 0.06 & 0.59 & 0.54 & 3.15 & 1.09 \\
\hline $\begin{array}{l}\text { I always wear N95 respirators during my entire shift } \\
\text { for maximum protection. }\end{array}$ & $\mathrm{C} 2$ & 0.27 & 0.16 & 0.56 & 0.50 & 3.14 & 1.17 \\
\hline $\begin{array}{l}\text { I am frequently tested for } C O V I D-19 \text {, although } I \text { do not } \\
\text { have symptoms. }\end{array}$ & C3 & 0.33 & 0.24 & 0.54 & 0.50 & 3.36 & 1.04 \\
\hline Eigenvalues & - & 4.73 & 2.20 & 1.22 & - & - & - \\
\hline Loading of $\%$ variation & - & 25.39 & 22.05 & 10.05 & - & - & - \\
\hline
\end{tabular}


The label given to the first factor was worry because the four items with loadings from 0.82 as the highest to 0.65 as the lowest explained this variable. The highest loading was "I am worried that I may have the coronavirus if have the flu or common cold" (loading 0.82, $\mathrm{M}=3.05, \mathrm{SD}=1.10$ ). The factors regarding the nurses were worried about infection while they cared for COVID-19 patients and worried about their families showed good loadings at 0.79 and 0.66 , respectively. Regarding the second factor, the loadings of items ranged from 0.88 as the highest to 0.69 as the lowest. The factor was labeled compliance of the nurses. The highest item was related to the importance of updating their knowledge of COVID-19 (loading $=0.88, \mathrm{M}=3.05, \mathrm{SD}=1.10$ ), followed by the importance of using PPE, educating patients about COVID-19, and following the WHO guidelines ( $0.77,0.72$, and 0.69 , respectively). The last factor was related to cautiousness: three items loaded from 0.59 as the highest to 0.54 as the lowest. The highest loading was "Excessive disinfectants are used to disinfect hand from germs" ( $\mathrm{m}=3.15, \mathrm{SD}=1.09)$, followed by exaggerated use of PPE and exaggerated adherence to WHO guidelines.

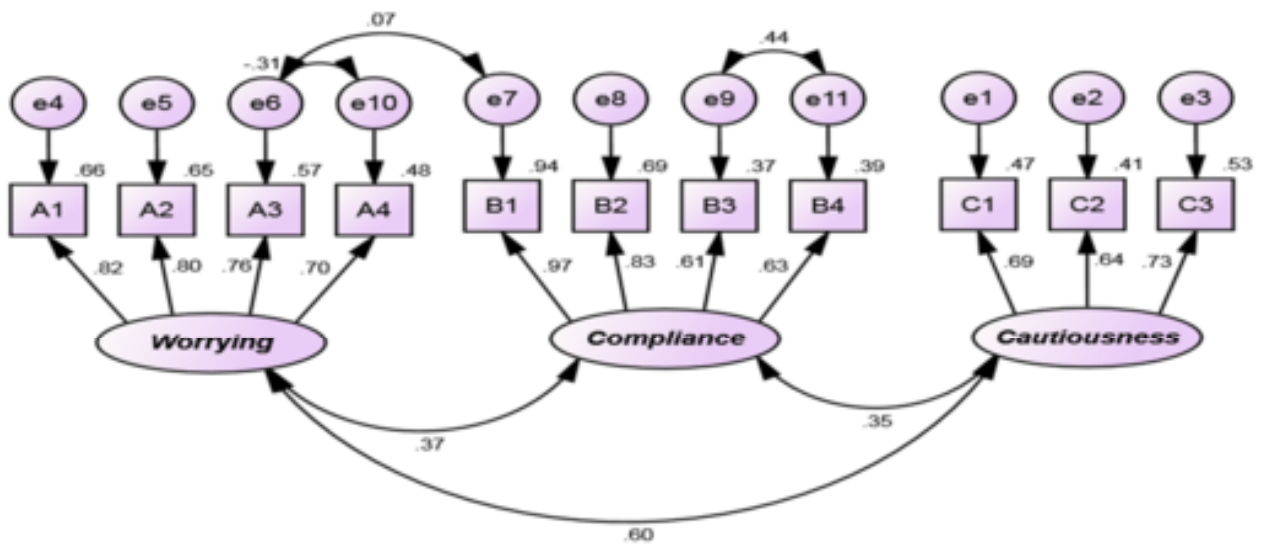

Model Fit Summary: CMIN = 60.966 DF= $39 \mathrm{P}=0.12 ; \mathrm{GFI}=0.93 ; \quad R M R=0.07 ; \mathrm{CFI}=0.97 \mathrm{RFI} \mathrm{Delta2}=0.97 ;$ RMSEA $=0.06 ; \mathrm{TL}$ i tho2 $=0.95$ Standardized $R M R=.0633$

Figure 4: CFA of all factors

All factors were tested using the model shown in Figure 3. All the residual covariances of the remaining items were in the range of normal values $(+1.96$ to -1.96$)$. The fitness scores for the three factors indicated that the model had good fitness (chi-square $=60.97$, DF $=39$ ). The $\mathrm{p}$ values, which must be higher than 0.05 , were insignificant. In addition, GFI $=0.39$; RMR $=0.07$; CFI $=0.97$; RFI DELTA2 $=0.97$; RMESA $=0.06$; TLI $=$ rho2 $=0.95$, and standardized $\mathrm{RMR}=0.06$. All were within the accepted range in confirming the goodness of fit, which also confirmed that the three factors extracted by EFA were valid.

Table 4: Estimation of variances

\begin{tabular}{cccccc}
\hline Variables & Estimate & S.E. & C.R. & P & Label \\
\hline Cautiousness & 0.56 & 0.153 & 3.70 & $* * *$ & par_15 \\
Worrying & 0.80 & 0.152 & 5.27 & $* * *$ & par_16 \\
Compliance & 0.75 & 0.112 & 6.70 & $* * *$ & par_17 \\
e1 & 0.62 & 0.115 & 5.45 & $* * *$ & par_18 \\
e2 & 0.80 & 0.131 & 6.19 & $* * *$ & par_19 \\
e3 & 0.50 & 0.103 & 4.88 & $* * *$ & par_20 \\
e4 & 0.40 & 0.073 & 5.52 & $* * *$ & par_21 \\
e5 & 0.50 & 0.088 & 5.71 & $* * *$ & par_22 \\
e6 & 0.63 & 0.109 & 5.83 & $* * *$ & par_23 \\
e7 & 0.05 & 0.047 & 1.05 & 0.291 & par_24 \\
e8 & 0.34 & 0.063 & 5.43 & $* * *$ & par_25 \\
e9 & 0.77 & 0.103 & 7.46 & $* * *$ & par_26 \\
e10 & 0.56 & 0.089 & 6.37 & $* * *$ & par_27 \\
e11 & 0.67 & 0.090 & 7.53 & $* * *$ & par_28 \\
\hline
\end{tabular}


The variance estimations for cautiousness, worry, and compliance significantly differed from zero at the 0.01 level (two-tailed), as shown in Table 4. Similarly, the variance estimates of e1, e2, e3, e4, e5, e6, e8, e9, e10, and e11 significantly differed from zero at the 0.01 level (two-tailed). However, the probability of a critical ratio for e 7 as large as 1.05 in absolute value was 0.291 . In other words, the variance estimate for compliance was not significantly different from zero at the 0.001 level (two-tailed). Therefore, another sample is needed to confirm its significance. After the confirmatory test, the reliability of the three factors (worry, compliance, and cautiousness) was tested using Cronbach's alpha (factor one $=0.84$; factor $2=0.86$; factor three $=0.73$ ), which indicated the good reliability of the scale: no factor was less than 0.70 .

\section{DISCUSSION}

Emergency nurses are on the frontlines, and they are the backbone of any health organization. Thus, it is important to understand their experiences during the COVID-19 pandemic for the improvement and development of nurses' planning, preparedness, response, and recovery from any pandemic crisis. In this study, the methodology was appropriate because it allowed for the analysis to be conducted using a sophisticated process to draw a reliable and valid conclusion about the experiences of emergency nurses during their responses to the COVID-19 pandemic in Saudi Arabia. Among the 22 items in the first version of the questionnaire, only 16 items passed the PCA, EFA, and CFA tests. Eleven items were deleted because they were weak, did not load to any factors, cross-loaded on two or more factors, or did not fit the final model. This approach is supported and strongly recommended in the literature because it ensures the validity and reliability of the scale. All redundant items must be removed because they had a negative impact on the real findings ${ }^{(22,23)}$. This study confirmed that three factors met the statistical requirement of goodness of fit: 1) worry, 2) compliance, and 3) cautiousness. The experiences of the emergency nurses were presented and summarized into factors that were extracted from the data after the EFA and CFA were applied.

In this study, the factor loadings for the four items related to the psychological reactions of nurses to COVID-19 ranged from 0.66 to 0.82, and they were highly significant. Based on these results, these items could be used to evaluate nurses' emotional reactions in encountering or dealing with COVID-19 patients. Because the mortality rate among COVID-19 patients is high ${ }^{(28)}$, the nurses were anxious and worried about the risk of being infected with COVID-19 when they care for confirmed COVID-19 patients. Others worried about their family. The high-transmission nature of the coronavirus has exacerbated nurses' worries. Furthermore, the constant coverage of the coronavirus across countries has created a sense of frustration among nurses because they see that even though their hospitals were prepared, the worst-case COVID-19 scenarios were experienced. These factors could have influenced the quality of nursing care ${ }^{(29)}$. Hence, it is highly recommended that nurses be provided with consistent support and reassurance to help them overcome such crises.

The literature shows that epidemic crises negatively affect individuals' psychological responses (30). Nevertheless, the psychosocial effects of the COVID-19 outbreak were neglected ${ }^{(31)}$. Indeed, the primary focus of COVID-19 management was how to control the spread of the infection ${ }^{(28,31)}$. To effectively break the chain of transmission of coronavirus disease, the psychological aspects of individuals should be considered ${ }^{(31)}$. It was important to consider the psychological effects on nurses during the outbreak of COVID-19 because of the negative effects of the crisis on individual cognition and rational thinking. Hence, it is highly recommended that individuals' worries and fears be considered in designing preventive measures and infection control programs.

The second factor confirmed in this study was related to the compliance of the nurses during their responses to the crisis. Four items were strongly loaded without cross loading to other factors. Nurses, including those who work in emergency departments, play significant roles in responding to any crisis. The COVID-19 pandemic involved treating infected and suspected patients as well as controlling and preventing the infection from spreading (32). However, this study identified that the nurses were responsible for updating their knowledge to manage patients with COVID-19. During crises, updating their knowledge is essential because it enhances clinical detection, adapting treatment, and discussing implications with patients, especially children, pregnant women, and chronically ill patients ${ }^{(33-35)}$. However, this results of this study indicated that there was no unified source for emergency nurses to acquire updated information. Most of the participants in the present study acquired information about COVID-19 from the Ministry of Health in Saudi Arabia. The Ministry of Health frequently updated all guidelines on a continuous basis. Healthcare providers, including nurses, could access the guidelines easily, which were comprehensive, including the following: control and prevention; therapeutic protocols for people with chronic diseases; protocols for infected pregnancy women; radiology; nutrition; dental; triage; CPR; admissions to hospital units and wards; physical therapy, and so on. However, accessing this information was one of the challenges for nurses during this crisis because of the lack of evidence and frequent changes. Similar challenges were encountered internationally. For example, nurses in Iran relied on the WHO and the ministry of health in that country ${ }^{(11)}$. This finding could guide the improvement of continuous education and training for emergency nurses in Saudi Arabia. However, details about the 
information and its quality were beyond the scope of this study. Nevertheless, further studies on these issues using different approaches, such as qualitative research, are recommended.

During crises such as the COVID-19 pandemic, the nurse's role is to build strength, which enables them to provide quality care to patients. Thus, the interim guidelines and the institution's protocol should be strictly followed. It is important that nurses maintain precautions and follow the guidelines, which was confirmed in this study. The core responsibilities of nurses are to provide holistic patient care, which includes education and instructions that enhance health promotion. Similarly, when emergency nurses respond to COVID-19, they must educate their patients and provide them instructions according to the guidelines approved in their hospitals. Following guidelines, especially during this crisis, is essential in improving patient outcomes and reducing mortality and morbidity rates. The COVID-19 crisis has impacted healthcare systems worldwide and changed the level of services that were provided before the pandemic. The literature shows that during disasters, because nurses lack guidelines and protocols, they face challenges in managing the crisis. Thus, nurses must be kept up to date with the knowledge needed to enhance their competencies according to approved protocols. If protocols and guidelines are lacking, nurses must use critical thinking and develop plans according to the needs of their patients ${ }^{(35-37)}$.

The third factor confirmed in this study was related to the cautiousness of emergency nurses, which was strongly loaded on three items. According to the WHO (2020), washing hands is an essential prevention measure that can limit the spread of COVID-19 ${ }^{(38)}$. However, damage of the hands skin is relatively common among nurses because of using large amount of hand sanitizers during hand washing ${ }^{(39,40)}$. The high prevalence of damage to the skin on the hands of nurses and healthcare workers was reported during the COVID-19 pandemic ${ }^{(41)}$. Previous studies showed that the quality, rather than the quantity, of the hand sanitizers is a significant factor ${ }^{(42)}$. Indeed, disinfectants with ethanol as the main element are highly recommended for hand hygiene ${ }^{(43)}$. Because of the increased risk of damage to the skin on the hands, proper instructions must be provided to nurses during the COVID-19 pandemic.

Screening nurses and other healthcare workers for COVID-19 depends on the hospital's policies. However, nurses should monitor themselves regularly for signs and symptoms of the coronavirus. Unfortunately, previous studies showed that nurses with confirmed COVID-19 may continue to work for few days although they are experiencing symptoms of the coronavirus ${ }^{(44)}$. Thus, wearing masks is recommended to protect both patients and coworkers from being infected. Furthermore, masks provide both respiratory protection and source control ${ }^{(38)}$.

Respirator masks such as N95 are preferred during aerosol-generating procedures. Surgical masks are recommended in dealing with patients who are not infected with COVID-19 ${ }^{(45)}$.Precautions should be used in caring for patients who are not suspected of having COVID-19. The reason is that not all patients with COVID19 exhibit symptoms. Previous studies indicated that some patients are asymptomatic, and the COVID-19 test does not always detect the virus.

\section{CONCLUSION}

This study identified three factors that reflect emergency nurses' response to the COVID-19 crisis: worry, compliance, and cautiousness. Nurses comply with infection control prevention measures, and they are cautious while maintaining maximum protection. However, most importantly, the findings suggest that there is certain degree of psychological impact on emergency nurses because they encounter and deal with the COVID19 crisis. This needs to be considered in designing preventive measures and infection control programs. To help nurses to overcome the COVID-19 crisis, an appropriate and consistent supportive system should be implemented. Without this system, nurses may experience significant stress and anxiety. Further studies are needed to fully understand emergency nurses' responses to pandemics in general and COVID-19 in particular.

\section{REFERENCES}

1. Brooke J, Jackson D. Older people and COVID-19: Isolation, risk and ageism. Journal of clinical nursing. 2020.

2. Usher K, Bhullar N, Durkin J, Gyamfi N, Jackson D. Family violence and COVID-19: Increased vulnerability and reduced options for support. International journal of mental health nursing. 2020.

3. Collaborative C, Nepogodiev D, Bhangu A. Elective surgery cancellations due to the COVID-19 pandemic: global predictive modelling to inform surgical recovery plans. British Journal of Surgery. 2020.

4. Strouse PJ. Pediatric radiology and the COVID-19 pandemic. Pediatric Radiology. 2020:1.

5. Noreen N, Dil S, Niazi S, Naveed I, Khan N, Khan F, et al. COVID 19 Pandemic \& Pakistan; Limitations and Gaps. Global Biosecurity. 2020;1(4).

6. Arango C. Lessons Learned From the Coronavirus Health Crisis in Madrid, Spain: How COVID-19 Has 
Changed Our Lives in the Last 2 Weeks. Biological Psychiatry. 2020.

7. Jackson D, Bradbury-Jones C, Baptiste D, Gelling L, Morin K, Neville S, et al. Life in the pandemic: Some reflections on nursing in the context of COVID-19. Journal of clinical nursing. 2020.

8. Alharbi J, Jackson D, Usher K. The potential for COVID-19 to contribute to compassion fatigue in critical care nurses. Journal of Clinical Nursing. 2020.

9. Li Z, Ge J, Yang M, Feng J, Qiao M, Jiang R, et al. Vicarious traumatization in the general public, members, and non-members of medical teams aiding in COVID-19 control. Brain, behavior, and immunity. 2020.

10. Liu Z, Han B, Jiang R, Huang Y, Ma C, Wen J, et al. Mental health status of doctors and nurses during COVID-19 epidemic in China. Available at SSRN 3551329. 2020.

11. Nemati M, Ebrahimi B, Nemati F. Assessment of Iranian nurses' knowledge and anxiety toward COVID-19 during the current outbreak in Iran. Archives of Clinical Infectious Diseases. 2020;15(COVID-19).

12. Lobb EA, Kristjanson LJ, Aoun SM, Monterosso L, Halkett GK, Davies A. Predictors of complicated grief: A systematic review of empirical studies. Death studies. 2010;34(8):673-98.

13. Wallace CL, Wladkowski SP, Gibson A, White P. Grief during the COVID-19 pandemic: considerations for palliative care providers. Journal of Pain and Symptom Management. 2020.

14. Chirico F, Nucera G, Magnavita N. COVID-19: Protecting Healthcare Workers is a priority. Infection Control \& Hospital Epidemiology. 2020:1-.

15. Huang L, Lin G, Tang L, Yu L, Zhou Z. Special attention to nurses' protection during the COVID-19 epidemic. BioMed Central; 2020.

16. Morley G, Grady C, McCarthy J, Ulrich CM. Covid-19: Ethical Challenges for Nurses. Hastings Center Report. 2020.

17. Daly J, Jackson D, Anders R, Davidson PM. Who speaks for nursing? COVID-19 highlighting gaps in leadership. Journal of Clinical Nursing.n/a(n/a).

18. Ebrahim SH, Ahmed QA, Gozzer E, Schlagenhauf P, Memish ZA. Covid-19 and community mitigation strategies in a pandemic. British Medical Journal Publishing Group; 2020.

19. Ebrahim SH, Memish ZA. Saudi Arabia's drastic measures to curb the COVID-19 outbreak: temporary suspension of the Umrah pilgrimage. Journal of Travel Medicine. 2020;27(3):taaa029.

20. Asaad A, El-Sokkary R, Alzamanan M, El-Shafei M. Knowledge and attitudes towards middle east respiratory sydrome-coronavirus (MERS-CoV) among health care workers in South-Western Saudi Arabia. Eastern Mediterranean Health Journal. 2020;26(4):435-42.

21. Stirling BV, Harmston J, Alsobayel H. An educational programme for nursing college staff and students during a MERS- coronavirus outbreak in Saudi Arabia. BMC Nursing. 2015;14(1).

22. Williams B, Onsman A, Brown T. Exploratory factor analysis: A five-step guide for novices. Australasian Journal of Paramedicine. 2010;8(3).

23. Kline RB. Principles and practice of structural equation modeling: Guilford publications; 2015.

24. Bartlett MS. A note on the multiplying factors for various $\chi 2$ approximations. Journal of the Royal Statistical Society Series B (Methodological). 1954:296-8.

25. Pett MA, Lackey NR, Sullivan JJ. Making sense of factor analysis: The use of factor analysis for instrument development in health care research: sage; 2003.

26. SPSS. SPSS version 24 (IBM Corp. Released 2016. IBM SPSS Statistics for Mac, Version 24.0. Armonk, NY, USA).

27. Arbuckle JL. Amos (version 23.0)[computer program]. Chicago: IBM SpSS. 2014.

28. Baud D, Qi X, Nielsen-Saines K, Musso D, Pomar L, Favre G. Real estimates of mortality following COVID-19 infection. Lancet Infect Dis. 2020.

29. Buheji M, Buhaid N. Nursing Human Factor During COVID-19 Pandemic. International Journal of Nursing. 2020;10(1):12-24.

30. Pappas G, Kiriaze I, Giannakis P, Falagas M. Psychosocial consequences of infectious diseases. Clinical microbiology and infection. 2009;15(8):743-7.

31. Ahorsu DK, Lin C-Y, Imani V, Saffari M, Griffiths MD, Pakpour AH. The fear of COVID-19 scale: development and initial validation. International journal of mental health and addiction. 2020.

32. Smith GD, Ng F, Li WHC. COVID-19: Emerging compassion, courage and resilience in the face of misinformation and adversity. Journal of Clinical Nursing. 2020;29(9-10):1425.

33. Al Thobaity A, Plummer V, Innes K, Copnell B. Perceptions of knowledge of disaster management among military and civilian nurses in Saudi Arabia. Australasian Emergency Nursing Journal. 2015;18(3):156-64.

34. Al Thobaity A, Plummer V, Williams B. What are the most common domains of the core competencies of disaster nursing? A scoping review. International Emergency Nursing. 2017;31:64-71.

35. Schultz CH, Koenig KL, Whiteside M, Murray R, Force NSA-HDCCT. Development of national standardized all-hazard disaster core competencies for acute care physicians, nurses, and EMS professionals. Annals of emergency medicine. 2012;59(3):196-208. e1.

36. Al Thobaity A, Alamri S, Plummer V, Williams B. Exploring the necessary disaster plan components in 
Saudi Arabian hospitals. International Journal of Disaster Risk Reduction. 2019;41:101316.

37. Al Thobaity A, Williams B, Plummer V. A new scale for disaster nursing core competencies: Development and psychometric testing. Australas Emerg Nurs J. 2016;19(1):11-9.

38. Organization WH. Advice on the use of masks in the context of COVID-19: interim guidance, 5 June 2020. World Health Organization; 2020.

39. Skoet R, Olsen J, Mathiesen B, Iversen L, Johansen JD, Agner T. A survey of occupational hand eczema in Denmark. Contact dermatitis. 2004;51(4):159-66.

40. Flyvholm MA, Bach B, Rose M, Jepsen KF. Self-reported hand eczema in a hospital population. Contact Dermatitis. 2007;57(2):110-5.

41.Lan J, Song Z, Miao X, Li H, Li Y, Dong L, et al. Skin damage among health care workers managing coronavirus disease-2019. Journal of the American Academy of Dermatology. 2020;82(5):1215-6.

42. Cavanagh G, Wambier CG. Rational hand hygiene during the coronavirus 2019 (COVID-19) pandemic. Journal of the American Academy of Dermatology. 2020;82(6):e211.

43. Yan Y, Chen H, Chen L, Cheng B, Diao P, Dong L, et al. Consensus of Chinese experts on protection of skin and mucous membrane barrier for health-care workers fighting against coronavirus disease 2019. Dermatologic Therapy. 2020:e13310.

44. Chow EJ, Schwartz NG, Tobolowsky FA, Zacks RL, Huntington-Frazier M, Reddy SC, et al. Symptom screening at illness onset of health care personnel with SARS-CoV-2 infection in King County, Washington. Jama. 2020.

45. Adir Y, Segol O, Kompaniets D, Ziso H, Yaffe Y, Bergman I, et al. COVID-19: minimising risk to healthcare workers during aerosol-producing respiratory therapy using an innovative constant flow canopy. European Respiratory Journal. 2020;55(5). 